Supporting Information

\title{
Propyne Hydrogenation over a Pd/Cu(111) Single-Atom Alloy Studied using Ambient Pressure Infrared Spectroscopy
}

Mohammed K. Abdel-Rahman and Michael Trenary*

Department of Chemistry, University of Illinois at Chicago, 845 West Taylor Street, Chicago, Illinois 60607, United States

*Corresponding author: mtrenary@uic.edu

IR spectra of propyne, propene, and propane

Propyne, propene, and propane IR spectra were collected individually to identify unique

features to monitor the hydrogenation reaction. Figure S1 shows the IR spectra of the three gases

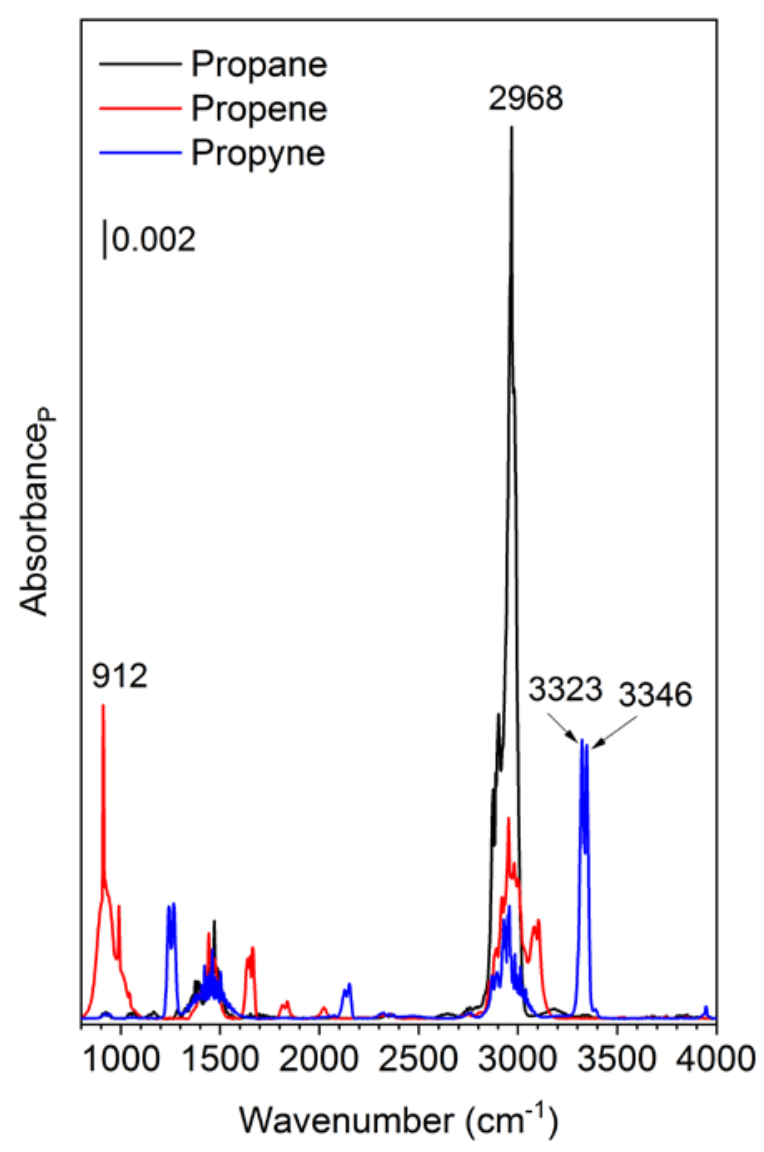

Figure S1: Infrared spectra of propyne, propene, and propane collected individually at 1 Torr. 
with the unique features identified. Propyne is identified by unique peaks at 1260, 2200, and $3330 \mathrm{~cm}^{-1}$ corresponding to the first overtone of the $\mathrm{C} \equiv \mathrm{C}-\mathrm{H}$ bend, the $\mathrm{C} \equiv \mathrm{C}$ stretch, and the $\equiv \mathrm{C}-\mathrm{H}$ stretch modes, respectively. Propyne has $\mathrm{C}_{3 \mathrm{v}}$ symmetry and its parallel vibrations have resolvable $\mathrm{P}$ and $\mathrm{R}$ branch envelopes. The most intense peak for propyne is the $\mathrm{P}$ branch of the $\equiv \mathrm{C}-\mathrm{H}$ stretch at $3323 \mathrm{~cm}^{-1}$. This peak was monitored to determine how much propyne was consumed during the hydrogenation reactions.

Propene exhibits unique features at 912 ( $\mathrm{CH}_{2}$ wagging), 991 (allylic $\mathrm{CH}$ bending), 1650 (C=C stretching), 1820, 2000, and $3100 \mathrm{~cm}^{-1}$ ( $\mathrm{CH}_{2}$ antisymmetric stretching). The peak at 1820 $\mathrm{cm}^{-1}$ is attributed to the combination of $\mathrm{CH}_{2}$ bending and $\mathrm{CH}$ stretching modes. The peak at 2000 $\mathrm{cm}^{-1}$ is attributed to the combination of the $\mathrm{CH}_{3}$ wagging and $\mathrm{CH}$ bending modes. These assignments are based on gas phase IR spectra of propene and propene- $\mathrm{d}_{6}$ by Lord and Venkateswarlu. ${ }^{1}$ The most intense peak for propene is the $\mathrm{CH}_{2}$ wagging mode at $912 \mathrm{~cm}^{-1}$. This peak was monitored to determine the amount of propene produced from the hydrogenation of propyne. Propene has $\mathrm{C}_{\mathrm{s}}$ symmetry and some of its rotational structure is partially revolved.

The major peak for propane is at $2968 \mathrm{~cm}^{-1}$ corresponding to the $\mathrm{CH}_{3}$ antisymmetric stretching mode. A peak at or near this value is observed for all three gases; however, it is significantly larger for propane than for propene and propyne at the same pressure. The antisymmetric methyl deformation mode at $1480 \mathrm{~cm}^{-1}$ overlaps with those of propene and propyne. Rotational fine structure is seen in all three gases for this mode. Propane would be noticeable as a hydrogenation product during the reaction because the $\mathrm{CH}_{3}$ stretching peaks would dominate the spectrum, as opposed to the $\mathrm{CH}_{2}$ bending or $\equiv \mathrm{C}-\mathrm{H}$ stretching peaks for propene and propyne, respectively. 
Propyne and propene amounts from IR spectra

Figure S2 shows the infrared absorbance of propyne $\left(3322 \mathrm{~cm}^{-1}\right)$ and propene $\left(912 \mathrm{~cm}^{-1}\right)$ as the pressure is sequentially increased to 1.0 Torr in the IR cell. The plots in the fig. S2 were fitted to the Beer-Lambert Law $A=\varepsilon l c$ relating absorbance to partial pressure. The slopes of the lines correspond to the value of $\varepsilon l$ in the Beer-Lambert Law. The amount of propyne consumed during the reaction was calculated by converting IR absorbance to partial pressure then pressure to moles using the known temperature and volume of the IR cell.
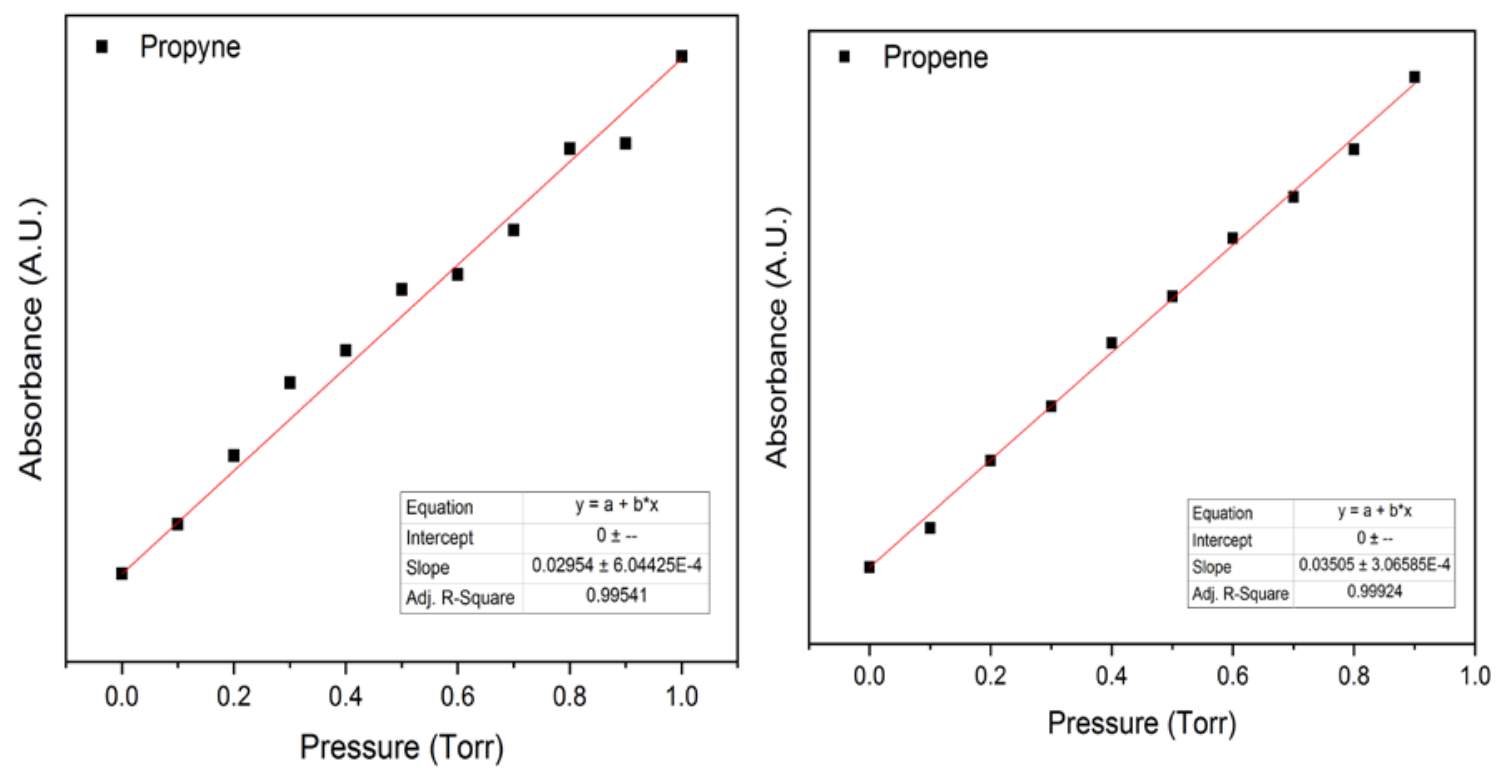

Figure S2: To relate IR absorbance to amount of propyne or propene in the reaction, 10 point calibration curves were generated by increasing the partial pressure of each gas in the IR cell by 0.1 Torr increments. 
Surface composition by AES

The hydrogenation reaction over $\mathrm{Cu}$ and $2 \% \mathrm{Pd} / \mathrm{Cu}$ surfaces was characterized by AES.

The C KVV, Pd MNN, and Cu LMM transitions are shown in Figure S3. The Auger spectra compare how propyne interacts with both surfaces. After annealing at $500 \mathrm{~K}$ under $50 \mathrm{mTorr}$ of propyne and 150 mTorr of $\mathrm{H}_{2}$, the Cu catalyst has a surface composition of $71 \%$ carbon and $29 \%$ copper. After annealing at $1000 \mathrm{~K}$, carbon-containing species were desorbed reducing the surface composition to $56 \%$ carbon and $44 \%$ copper. The $2 \% \mathrm{Pd} / \mathrm{Cu}$ surface composition becomes $68 \%$ carbon, $0.9 \%$ palladium, and $31.9 \%$ copper after annealing to $500 \mathrm{~K}$. Approximately half of the palladium atoms diffuse into the $\mathrm{Cu}(111)$ crystal after annealing at $500 \mathrm{~K}$. Upon annealing at $1000 \mathrm{~K}$, carbon-containing species desorb from the surface and the remaining surface
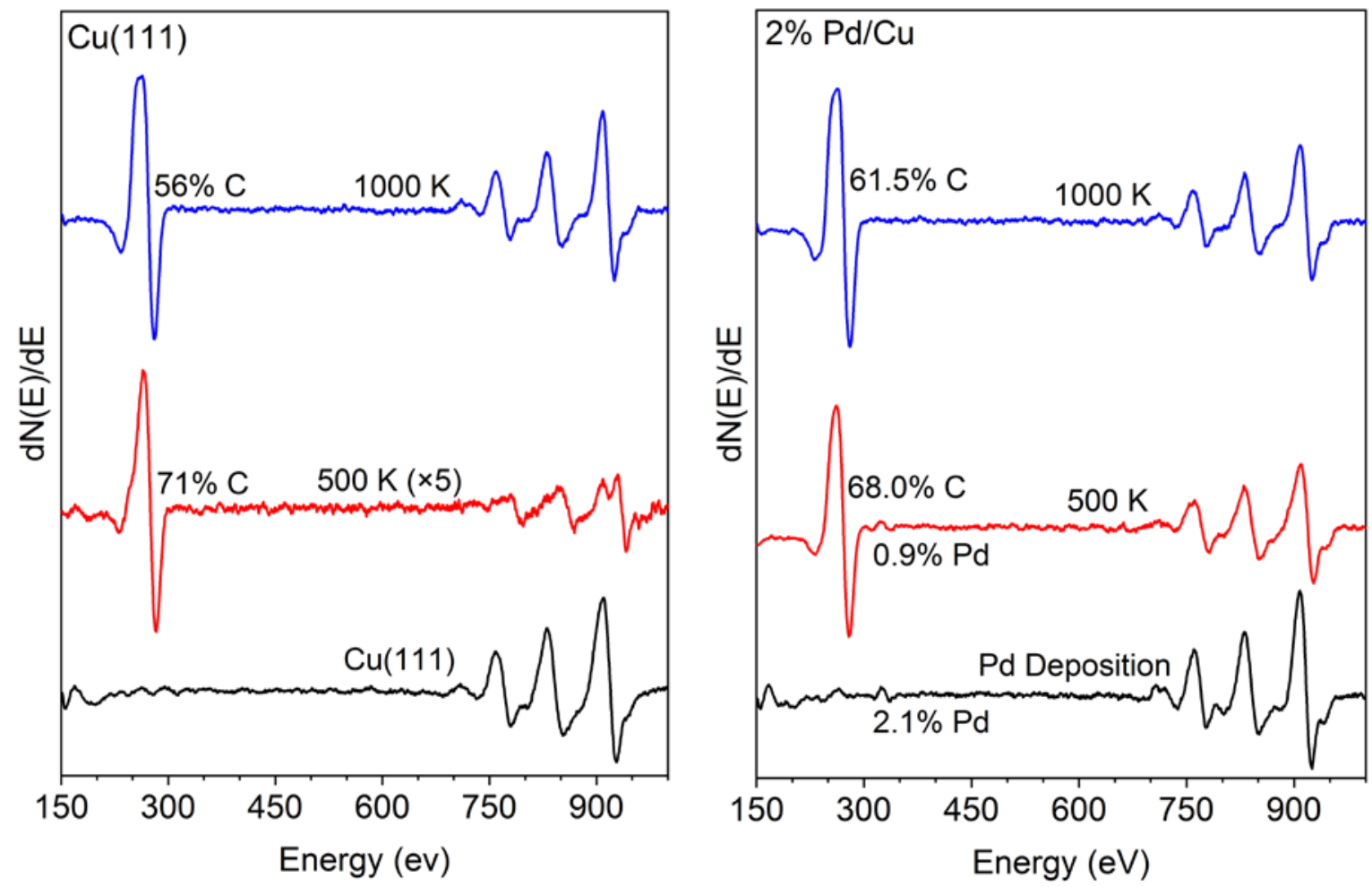

Figure S3: Auger spectra were collected from 150-1000 eV with a beam energy of $2.5 \mathrm{kV}$. The black spectra correspond to the catalyst after surface preparation. The red spectra were collected after annealing each catalyst in an ambient of 50 mTorr propyne and $150 \mathrm{mTorr}_{2}$ at $500 \mathrm{~K}$ for one minute. The blue spectra were collected after heating the catalyst to 1000 $\mathrm{K}$ in UHV during the TPD studies. 
composition becomes 61.5\% carbon and 38.5\% copper. From the Auger spectra in figure S2, the presence of palladium facilitates carbon removal at $500 \mathrm{~K}$.

Similar Auger spectra, shown in figure S4 were collected for propene interacting with the two surfaces. In both cases, carbon deposited from propene exposure fris more easily removed than from propyne exposure by annealing at $500 \mathrm{~K}$. The Cu catalyst surface is composed of $50 \%$ carbon after annealing at $500 \mathrm{~K}$. The carbon layer becomes slightly denser as $\mathrm{H}_{2}$ is evolved when heated to $1000 \mathrm{~K}$. The $2 \% \mathrm{Pd} / \mathrm{Cu}$ surface consists of only $14 \%$ carbon when annealed at $500 \mathrm{~K}$ indicating that desorption of carbon-containing species is greatly enhanced by the presence of palladium. More carbon is removed from the surface when heated to $1000 \mathrm{~K}$.
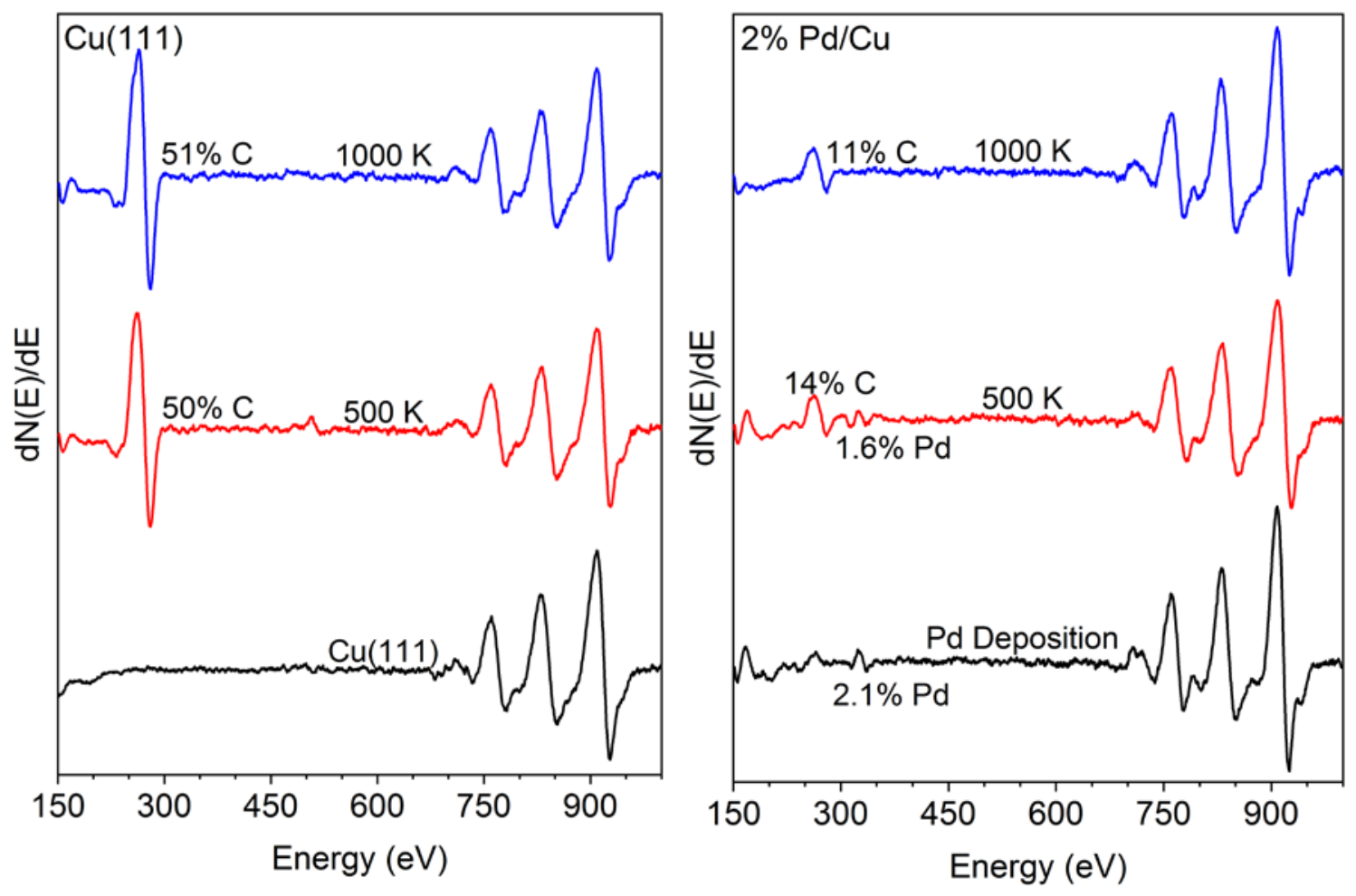

Figure S4: Auger spectra were collected from $150-1000 \mathrm{eV}$ with a beam energy of $2.5 \mathrm{kV}$. The black spectra correspond to the catalyst after surface preparation. The red spectra were collected after annealing each catalyst in an ambient of 50 mTorr propene and $150 \mathrm{mTorr}$ $\mathrm{H}_{2}$ at $500 \mathrm{~K}$ for one minute. The blue spectra were collected after heating the catalyst to $1000 \mathrm{~K}$ in UHV for TPD studies. 
After the reaction of 500 mTorr of propyne with 1500 mTorr of $\mathrm{H}_{2}$ at $383 \mathrm{~K}$, both the $\mathrm{Cu}$ and 2\%PdCu catalyst surfaces are coated in carbon. The Auger spectra in figure S5 show that after the reaction completed, the only Auger transition observed is C KVV. The Cu LMM and Pd MNN transitions were not detected. Since there was a propene yield of 50\% under these conditions, it is likely the remaining $16 \mu \mathrm{mol}$ of propyne either oligomerized or decomposed to form this carbonaceous layer.
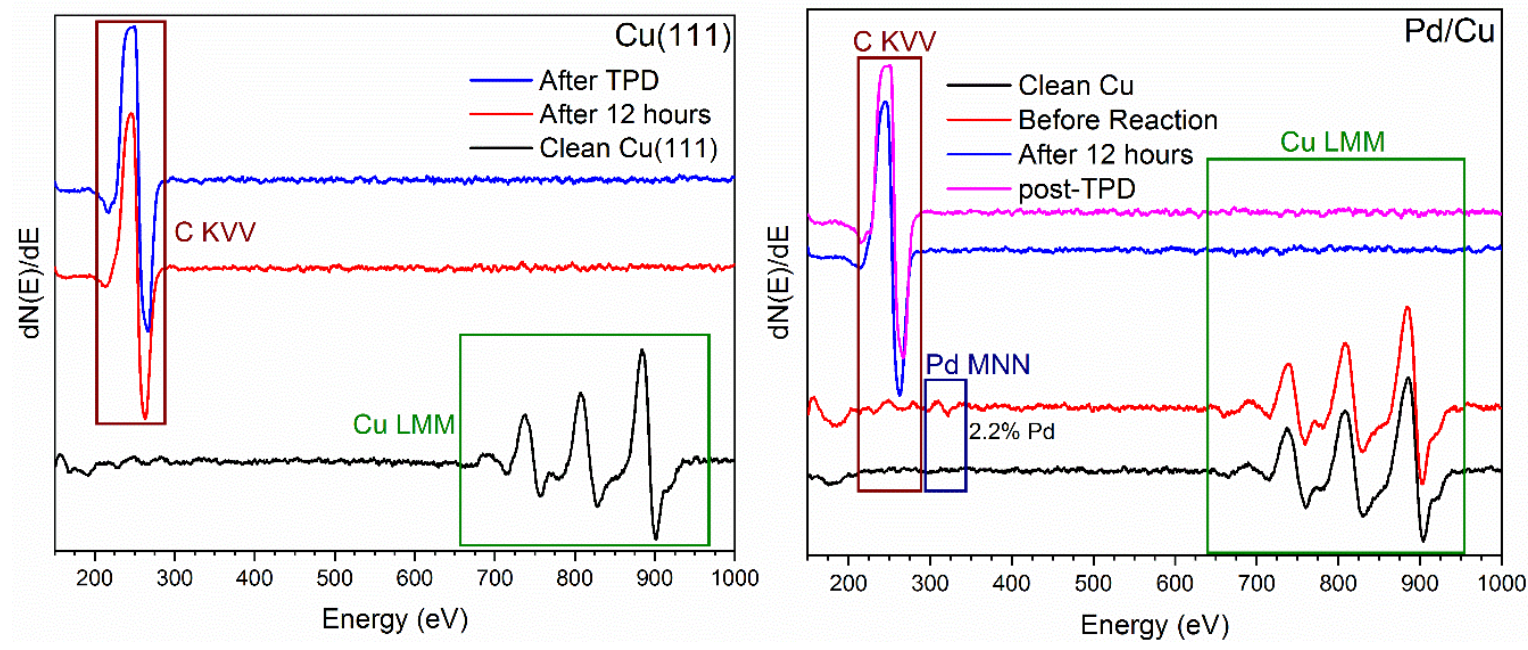

Figure S5: Auger spectra of the catalyst surface after propyne hydrogenation at $383 \mathrm{~K}$ after 12 hours and after heating to $1000 \mathrm{~K}$ in the course of obtaining TPD results. A carbonaceous layer coats both surfaces after the reaction is completed. 


\section{References:}

(1) Lord, R. C.; Venkateswarlu, P. The Infrared Spectra of Propylene and Propylene- $\mathrm{D}_{6} . J$. Opt. Soc. Am. 1953, 43, 1079. 